\title{
Antioxidant and Anti-Inflammatory Activities of Kigelia africana (Lam.) Benth.
}

\author{
Alice Nabatanzi $\left(\mathbb{D},{ }^{1,2,3,4,5}\right.$ Sanah M. Nkadimeng, ${ }^{2}$ Namrita Lall, ${ }^{3,6,7}$ John D. Kabasa, ${ }^{4}$ \\ and Lyndy J. McGaw ${ }^{2}$ \\ ${ }^{1}$ Department of Plant Sciences, Microbiology and Biotechnology, College of Natural Sciences, Makerere University, \\ Kampala 00256, Uganda \\ ${ }^{2}$ Phytomedicine Programme, Department of Paraclinical Sciences, Faculty of Veterinary Science, University of Pretoria, \\ Onderstepoort 0110, South Africa \\ ${ }^{3}$ Department of Plant and Soil Sciences, University of Pretoria, Hatfield 0028, South Africa \\ ${ }^{4}$ College of Veterinary Medicine, Animal Resources and Biosecurity, Makerere University, Kampala 00256, Uganda \\ ${ }^{5}$ Future Africa, University of Pretoria, Hatfield 0028, South Africa \\ ${ }^{6}$ School of Natural Resources, University of Missouri, Columbia 65211, USA \\ ${ }^{7}$ College of Pharmacy, JSS Academy of Higher Education and Research, Mysuru, Karnataka 570015, India
}

Correspondence should be addressed to Alice Nabatanzi; alice2nabatanzi@gmail.com

Received 23 March 2020; Accepted 5 May 2020; Published 17 June 2020

Academic Editor: Armando Zarrelli

Copyright (c) 2020 Alice Nabatanzi et al. This is an open access article distributed under the Creative Commons Attribution License, which permits unrestricted use, distribution, and reproduction in any medium, provided the original work is properly cited.

\begin{abstract}
Kigelia africana is used to manage inflammation among indigenous communities. We hypothesized that $K$. africana extracts contain phytoconstituents with good antioxidant and anti-inflammatory activities. The methanolic extract of $K$. africana fruits and Spathodea campanulata leaves (SPK04), K. africana aqueous fruit extract (KFM02), and K. africana acetone fruit extract (KFM05) were subjected to antioxidant and anti-inflammatory assays. Antioxidant activity was evaluated using the ABTS radical scavenging assay, and the MTT cell viability assay was used for cytotoxicity. The extracts were preincubated with enzymes and assayed for 15LOX and COX-2 enzyme activity using an ELISA method. Nitric oxide (NO) inhibitory effect of the extracts was evaluated and measurement of proinflammatory cytokines (IL- $1 \beta$, TNF- $\alpha$, and IL-6) and the anti-inflammatory cytokine (IL-10) was done using ELISA kits. SPK04 had the highest antioxidant activity with a mean inhibition of $99.37 \pm 0.56 \%$ and an $\mathrm{IC}_{50}$ of $4.28 \mu \mathrm{g} / \mathrm{mL}$. SPK04 and KFM05 did not inhibit 15-LOX as their $\mathrm{IC}_{50}$ values were $>1000 \mu \mathrm{g} / \mathrm{mL}$. All extracts were safe on Vero cells at the highest concentration $(200 \mu \mathrm{g} / \mathrm{mL})$ tested. KFM02 was the best inhibitor of NO production and had the highest cell viability at both the lowest $(50 \mu \mathrm{g} / \mathrm{mL})$ and highest concentrations $(200 \mu \mathrm{g} / \mathrm{mL})$. SPK04 was the best COX-2 inhibitor while KFM05 expressed the strongest suppression effect for IL- $\beta$ and IL-6. KFM02 did not inhibit IL-6 at the highest concentration $(200 \mu \mathrm{g} / \mathrm{mL})$. The order of suppression of TNF- $\alpha$ by the extracts differed across concentrations, KFM05 $>$ SPK04 $>$ KFM02 at $200 \mu \mathrm{g} / \mathrm{mL}$, KFM02 $>$ SPK04 $>$ KFM05 at $100 \mu \mathrm{g} / \mathrm{mL}$, and SPK04 $>$ KFM02 $>$ KFM05 at $50 \mu \mathrm{g} / \mathrm{mL}$. All the tested extracts had no inhibitory effect against IL-10. SPK04, KFM05, and KFM02 had good antioxidant and anti-inflammatory activity and this supports their use as potential anti-inflammatory therapies. This study presents for the first time the antioxidant and anti-inflammatory activity of $K$. africana and $S$. campanulata polyherbal extract. It is also among the very few studies that have reported the inhibitory effect of cytokines IL-1 $\beta$, TNF- $\alpha$, IL- 6 , and IL-10 by K. africana.
\end{abstract}

\section{Introduction}

Inflammation is the body's first protective mechanism to enable tissue healing when faced with injurious stimuli [1].
The body responds to inflammation by releasing proinflammatory cytokines such as interleukins (IL- $1 \beta$ and IL-6), interferons (IFN), and tumor necrosis factor-alpha (TNF- $\alpha$ ) among others [2]. This is followed by induction of 
cyclooxygenase-2 (COX-2) which then synthesizes prostaglandins (PGs) that contribute to inflammation, swelling, and pain [3]. Lipoxygenase (LOX) metabolises arachidonic acids to leukotrienes, a group of inflammatory mediators [4]. Furthermore, when macrophages are activated, they produce reactive oxygen species (ROS) which cause oxidative stress (OS). Oxidative stress is an inflammatory mediator which stimulates the release of proinflammatory cytokines and nitric oxide (NO) [5]. Nitric oxide contributes to the exacerbation of inflammatory diseases, inhibits mitochondrial enzymes, and activates COXs to produce PGs [6]. Therefore, an inhibitor of COX-2, LOX, NO, and ROS is likely to be effective in preventing and treating inflammatory diseases. The conventional treatment for inflammation is the use of nonsteroidal anti-inflammatory drugs (NSAIDs) [7] among others, but prolonged use of such substances results in toxic effects. A variety of plant constituents such as coumarins, carotenoids, and flavonoids [8] have been isolated and shown to have anti-inflammatory activities both in vitro and in vivo. Hence, the treatment of inflammatory diseases by herbal drugs has been of interest to researchers.

Several scholars have reported $K$. africana's traditional uses as an anti-inflammatory among other uses in various communities. K. africana fruits boiled with milk are used in Botswana to treat sexually transmitted diseases; the bark of $K$. africana is used in Nigeria to treat inflammation, dysentery, and cancer $[9,10]$, and $K$. africana fruits are used as anti-inflammatories in Kenya, Embu community [11]. Furthermore, antioxidant [12-14] and anti-inflammatory studies $[15,16]$ have been conducted on the various parts of $K$. africana and the species has proven effective. The anti-inflammatory activity of $S$. campanulata has also been documented and scientifically validated. In Senegal, bruised leaves and flowers of S. campanulata are applied to wounds [17] as a poultice. The methanol and aqueous extracts of $S$. campanulata leaves have been proven to have anti-inflammatory (paw edema induced by carrageenan) activity in rats [18]. Traditionally, K. africana has been used either as a single plant or in combination with other plants for increased potency. In Africa, K. africana, Hypoxis hemerocallidea, and Senecio serratuloides leaves and roots decoction is used to treat sexually transmitted infections and sores [19]. In Uganda, $S$. campanulata bark mixed with K. africana fruits is used as a dressing for wounds and in the treatment of various skin diseases. Therefore, S. campanulata's anti-inflammatory activity has been justified both traditionally and scientifically more reason for its adoption as a polyherbal with $K$. africana in the current study.

The anti-inflammatory activity of $K$. africana has been proposed to act by suppressing inflammatory mediators [20]. The present study ascertained the anti-inflammatory activity of $K$. africana extracts through the inhibition of ROS (antioxidant activity), 15-LOX, NO, COX-2, proinflammatory cytokines, and anti-inflammatory cytokines to enhance understanding of the possible mechanisms of activity against inflammation. The cytotoxicity on normal mammalian (Vero African green monkey kidney) cells was also established.

\section{Methods}

2.1. Plant Collection. Kigelia africana (leaves and fruits) and Spathodea campanulata Beauv. (leaves) were collected in the summer of April 2019 from Lynnwood, Pretoria East, South Africa. Voucher specimens for each of the plant species were prepared and deposited at the HGWJ Schweickerdt Herbarium, University of Pretoria. Herbarium voucher specimen numbers PRU/1/125491/Nabatanzi SA for K. africana and PRU/1/ 125492002/Nabatanzi SA for S. campanulata were assigned.

2.2. Plant Storage. The leaves of the two plant species were separated from their stems, cleaned of any extraneous matter, and dried separately for 14 days at room temperature. The fruits were washed with running tap water, cut into small pieces, and oven-dried at $40^{\circ} \mathrm{C}$ for 16 days. The dried plants were milled to a fine powder in a Macsalab mill (Model 200 LAB; Eriez, Bramley, South Africa) and stored at room temperature in closed containers in the dark until used.

2.3. Extraction Procedure. Extraction was done at a ratio of $1 \mathrm{~g}$ of finely ground plant material to $10 \mathrm{~mL}$ of solvent. Extracts were then prepared:

Extract 1 (SPK04): equal amounts of $K$. africana leaves $(250 \mathrm{~g})$ and $S$. campanulata leaves $(250 \mathrm{~g})$ were weighed into one big glass container and to it $5 \mathrm{~L}$ of methanol was added

Extract 2 (KFM02): $500 \mathrm{~g}$ of $K$. africana fruits was weighed into a big glass container and to it $5 \mathrm{~L}$ of hot water was added

Extract 3 (KFM05): $500 \mathrm{~g}$ of $K$. africana fruits was weighed into a big glass container and to it $5 \mathrm{~L}$ of acetone was added

All the solvents used were of technical grade (Merck, Johannesburg, South Africa). After adding the solvents to the powdered samples, the containers and contents were vigorously shaken for 20 minutes on a Labotec model 20.2 shaking machine at high speed. The containers of extracts were then covered with silver foil and macerated for 24 hours at room temperature. After 24 hours, the particulate matter of each extract had sedimented and the supernatant portion was filtered with $0.1 \mathrm{~mm}^{2}$ mesh gauze and then with Whatman No 1 filter paper with a pore size of $11 \mu \mathrm{m}$. The water extract (KFM02) was frozen at $-40^{\circ} \mathrm{C}$ and lyophilized in a VIRTIS Benchtop $2 \mathrm{~K}, 4 \mathrm{~K}$, and $6 \mathrm{~K}$ Freeze Dryer, United Scientific. The methanol (SPK04) and acetone (KFM05) extracts were evaporated using a rotavapor (R-114; Büchi, Newcastle, USA) and decanted into preweighed labelled beakers. The extracts were then placed under a stream of air in a fume cupboard at room temperature for further drying. On complete drying, they were stored at refrigerator temperature $\left(2-6^{\circ} \mathrm{C}\right)$ until used.

2.4. Antioxidant Activity: 2,2'-Azino-bis (3-Ethylbenzthiazoline-6-sulfonic Acid (ABTS) Radical Scavenging 
Assay. The ABTS radical scavenging capacity of the samples was measured as described by Re et al. [21]. Ascorbic acid was used as a positive control and the extract without ABTS as blank. $\mathrm{ABTS}^{+}$was generated by reacting $7 \mathrm{mM}$ ABTS aqueous solution with $2.4 \mathrm{mM}$ potassium persulfate in the dark for 16 hours at room temperature. Prior to assay, this solution was diluted in methanol and equilibrated at $30^{\circ} \mathrm{C}$ to give an absorbance of $0.7 \pm 0.02$ at $734 \mathrm{~nm}$ (BioTek Synergy microplate reader). Ten microlitres of each extract at different concentrations was added to $1 \mathrm{~mL}$ of diluted ABTS solution in U-bottom-shaped 96-well microplates. The plates were incubated for $5 \mathrm{~min}$ at $37^{\circ} \mathrm{C}$ under dark conditions, then the absorbance was measured at $734 \mathrm{~nm}$, and the percentage of inhibition was calculated. The percentage ABTS inhibition was calculated using the following formula:

$$
\begin{aligned}
& \text { scavenging capacity } \%=100 \\
& -\frac{\text { OD sample } * \text { OD sample blank }}{\text { OD control } * \text { OD control blank }} \times 100 \%,
\end{aligned}
$$

where OD is the absorbance.

The $\mathrm{IC}_{50}$ values were calculated from the graph plotted as inhibition percentage against the concentration.

2.5. Inhibition of 15-Lipoxygenase (15-LOX) Enzyme. The lipoxygenase inhibitor screening assay kit [22] was used to screen for inhibitors of 15-LOX. The 15-LOX (Sigma) was made up to a working solution of 200 units/mL and kept on ice. A volume of $12.5 \mu \mathrm{L}$ of test sample or control (dissolved in DMSO) was added to $487.5 \mu \mathrm{L}$ of $15-\mathrm{LOX}$ in a 96 -well microtitre plate and incubated at room temperature for $5 \mathrm{~min}$. After incubation, $500 \mu \mathrm{L}$ of substrate solutions $(10 \mu \mathrm{L}$ linoleic acid dissolved in $30 \mu \mathrm{L}$ ethanol, made up to $120 \mathrm{~mL}$ with $2 \mathrm{M}$ borate buffer at $\mathrm{pH}$ 9.0) was added to the solution. After $5 \mathrm{~min}$ incubation at room temperature, the absorbance was measured at $234 \mathrm{~nm}$. Quercetin $(1 \mathrm{mg} / \mathrm{mL})$ was used as a positive control, while DMSO was used as the negative control (100\% enzyme activity or no enzyme inhibition). The percentage enzyme inhibition of each extract compared with negative control as $100 \%$ enzyme activity was calculated using the following equation:

percent inhibition $(\%)=\frac{(\text { activity of control }- \text { activity of test })}{\text { activity of control }} \times 100$.

The results were expressed as $\mathrm{IC}_{50}$, i.e., concentration of the extracts and controls that resulted in 50\% 15-LOX inhibition plotted on a graph.

2.6. The 3-(4,5-Dimethylthiazol-2-yl)-2,5-diphenyl Tetrazolium Bromide (MTT) Cell Viability Assay. Cytotoxicity of each extract at different concentrations against Vero monkey kidney cells was determined as described by Mosmann [23]. Cells were seeded at a density of $1 \times 10^{5}$ cells/ $\mathrm{mL}(100 \mu \mathrm{L})$ in 96-well microtitre plates and incubated at $37^{\circ} \mathrm{C}$ and $5 \% \mathrm{CO}_{2}$ in a humidified environment. After 24hour incubation, extracts $(100 \mu \mathrm{L})$ at varying final concentrations were added to the wells containing cells. Doxorubicin $(0.38-40 \mu \mathrm{M})$ was used as a positive control. A suitable blank control with equivalent volume of acetone was also included, and the plates were further incubated at $3^{\circ} \mathrm{C}$ for 48 hours in a $\mathrm{CO}_{2}$ incubator. The medium was removed by aspiration, and cells were then washed twice with phosphatebuffered saline (PBS), followed by suspension in fresh medium $(200 \mu \mathrm{L})$. Then, $30 \mu \mathrm{L}$ of MTT $(5 \mathrm{mg} / \mathrm{mL}$ in PBS) was added to each well and the plates were incubated at $37^{\circ} \mathrm{C}$ for 4 hours. The medium was removed by aspiration and $100 \%$ DMSO $(100 \mu \mathrm{L})$ was added to dissolve the formed formazan crystals. The absorbance was measured using a microtitre plate reader (BioTek Synergy) at $570 \mathrm{~nm}$. The percentage of cell growth inhibition was calculated based on a comparison with that of untreated cells. The selectivity index (SI) values were calculated by dividing cytotoxicity $\mathrm{LC}_{50}$ values by the $\mathrm{MIC}$ values $\left(\mathrm{SI}=\mathrm{LC}_{50} / \mathrm{MIC}\right)$.

\subsection{Inhibition of Nitric Oxide (NO) Production}

2.7.1. Cell Culture. The RAW 264.7 macrophage cell line was obtained from the American Type Culture Collection (Rockville, MD, USA) and cultured in plastic culture flasks in Dulbecco's modified Eagle's medium (DMEM) containing l-glutamine supplemented with $10 \%$ foetal calf serum (FCS) and 1\% PSF (penicillin/streptomycin/fungizone) solution under $5 \% \mathrm{CO}_{2}$ at $37^{\circ} \mathrm{C}$ and was split twice a week.

All cells were seeded in 96-well microtitre plates and activated by incubation in medium containing LPS $(5 \mu \mathrm{g} /$ $\mathrm{mL}$ ), and various concentrations of extracts were dissolved initially in DMSO and made up to the required concentration in DMEM. Measurement of nitrite released from macrophages was assessed by the determination of nitrite concentration in the culture supernatant using the Griess reagent. After 24-hour incubation, $100 \mu \mathrm{L}$ of the supernatant from each well of the cell culture plates was transferred into 96-well microtitre plates and an equal volume of Griess reagent (Sigma) added. The absorbance of the resultant solutions in the wells of the microtitre plate was determined after $10 \mathrm{~min}$ at $550 \mathrm{~nm}$. The concentrations of nitrite were calculated from regression analysis using serial dilutions of sodium nitrite as a standard. Percentage inhibition was calculated based on the ability of extracts to inhibit nitric oxide formation by cells compared with the control (cells in media without extracts containing triggering agents and DMSO), which was considered as $0 \%$ inhibition.

2.8. Cyclooxygenase-2 (COX-2) Inhibition Assay. The COX inhibition screening assay directly measures PGF $2 \alpha$ by stannous chloride reduction of COX-derived PGH2 produced in the COX reaction [24]. The reaction system consists of reaction buffer, haem, enzyme, and plant extract preincubated at $37^{\circ} \mathrm{C}$ for $20 \mathrm{~min}$ with background and enzyme controls. The reaction was initiated with the addition of arachidonic acid and incubated for $2 \mathrm{~min}$ at $37^{\circ} \mathrm{C}$. The reaction was stopped with the addition of saturated stannous chloride solution for $5 \mathrm{~min}$ at room temperature. The prostaglandins were quantified by enzyme immunoassay technique (EIA). An aliquot of these reactions was added to the precoated plates in triplicate together with 
acetylcholinesterase (AChE) tracer and antiserum and incubated for 18 hours at room temperature on an orbital shaker. The plate was then finally developed with Ellman's reagent and kept on an orbital shaker in the dark at room temperature for 60 minutes. The absorbance was read at $420 \mathrm{~nm}$. The data were plotted as \%B/B0 (standard bound/ maximum bound) versus log concentration using a 4-parameter logistic curve fit. The concentration of each sample was determined from a standard curve with appropriate dilutions and used to calculate the percent inhibition as per the following formula:

percent inhibition $(\%)=\frac{(\text { activity of control }- \text { activity of test })}{\text { activity of control }} \times 100$.

The results were expressed as $\mathrm{IC}_{50}$, i.e., concentration of the extracts and controls that resulted in 50\% COX-2 inhibition plotted on a graph.

2.9. Cytokine Detection. RAW 264.7 macrophages were stimulated with LPS which led to the secretion of IL- $1 \beta$, TNF$\alpha$, IL-6, and IL-10 cytokines. Treatment with the plant extracts was then applied, and subsequently, the amounts of IL-1 $\beta$, TNF- $\alpha$, IL-6, and IL-10 were measured using commercial ELABSCIENCE ELISA kits: Mouse IL-6 ELISA Kit, Catalogue no: E-EL-M0044; Mouse TNF- $\alpha$ ELISA Kit, Catalogue no: E-EL-M0049; Mouse IL-10 ELISA Kit, Catalogue no. E-ELM0046; and Mouse IL-1 $\beta$ ELISA Kit, Catalogue no: E-ELM0037. The absorbance was read at $450 \mathrm{~nm}$ using a microtitre plate reader (BioTek Synergy). The amounts of IL- $1 \beta$, TNF- $\alpha$, IL-6, and IL-10 were calculated with the help of a standard curve, which was constructed using serial dilutions of cytokine standards provided with the kit. By comparing the OD of the samples to the standard curve, the concentration of the cytokines in the culture supernatant was determined.

2.10. Statistical Analysis. Results are expressed as mean\pm SEM of three independent experiments. Multigroup analysis was performed using one-way analysis of variance (ANOVA). Significance levels were set as $p<0.05$.

\section{Results and Discussion}

3.1. Kigelia africana Extracts Are Highly Potent Free Radical Scavengers. The percentage mean antioxidant capacity of the extracts is presented in Table 1 , and the mean $\mathrm{IC}_{50}$ values are presented in Table 2. Ascorbic acid was used as a standard with a mean antioxidant activity of $103.95 \pm 4.09 \%$ and $99.97 \pm 0.12 \%$ at $100 \mathrm{mg} / \mathrm{mL}$ and $1.56 \mathrm{mg} / \mathrm{mL}$ concentrations, respectively. The extracts scavenged the ABTS radical in a concentration-dependent manner. SPK04 possessed the best antioxidant activity, which was $99.37 \pm 0.56 \%$ and $18.03 \pm 4.25 \%$ at the highest and lowest concentrations, respectively. KFM02 showed the least antioxidant activity of $109.12 \pm 14.32 \%$ and $15.3 \pm 0.88 \%$ at the highest and lowest concentrations, respectively. If antioxidant $\mathrm{IC}_{50}$ values are $<50 \mu \mathrm{g} / \mathrm{mL}$, as was exhibited by SPK04, KFM05, and KFM02 with $4.28,19.47$, and $21.29 \mu \mathrm{g} / \mathrm{mL}$, respectively (Table 2 ), it is an indicator that the plant extracts are potent scavengers. Thus, the lower the $\mathrm{IC}_{50}$ value, the more potent is the substance at scavenging ABTS and this implies a higher antioxidant activity [25]. The antioxidant ranking order for the three plant extracts tested was SPK04 $>$ KFM05 > KFM02. Kigelinone and kigelinol were proposed to be the phytochemicals mainly responsible for $K$. africana's antioxidant power [26], although others may perhaps also be present. Additionally, free radical eradication by $K$. africana may be due to the presence of phenols that can donate the hydrogen atoms in their hydroxyl groups [27]. When the amount of ROS produced exceeds the antioxidant capability of the target cell, oxidative stress occurs [28]. Whereas ROS and NO exacerbate inflammation, antioxidants help in scavenging them, thus avoiding cellular injury and diseases [29]. Therefore, the antioxidant effect of Kigelia extracts could contribute to reinforcing their anti-inflammatory properties. Researchers have established the link between oxidants, inflammatory reactions, and infection. In chronic infection and inflammation, the release of leukocytes and other phagocytic cells defends the organism from further injury. The cells do this by releasing free oxidant radicals such as $\mathrm{NO}, \mathrm{O}_{2}^{-}, \mathrm{H}_{2} \mathrm{O}_{2}$, and $\mathrm{OH}^{-}$whose actions are inhibited by antioxidants [30].

Several researchers have reported the abundance of antioxidant compounds in plants, thereby justifying their role in scavenging free radicals, thus providing protection to humans against oxidative DNA damage [31-34]. Kigelia africana's antioxidant activity has been investigated by earlier researchers and the reported potency concurs with the results in the current study. A study by Hussein et al. [12] reported that the ethanolic bark (67.33\%), fruit (62.66\%), and leaf $(59.66 \%)$ extracts of $K$. africana possessed good antioxidant activity compared with the standard (quercetin) (94\%) in a DPPH assay. In another study, the methanolic stem bark extract of $K$. africana significantly scavenged DPPH stable radical by $53.2 \%$, compared to the standard ascorbic acid [14]. According to Olubunmi et al. [35], the free radical scavenging activities of $K$. africana root extract through spectrophotometric assay on the reduction of $\mathrm{DPPH}$ were compared favourably with $\alpha$-tocopherol (standard) at the highest concentration $(1000 \mu \mathrm{g} / \mathrm{mL})$. Our data, therefore, supported the findings of previous studies who reported strong antioxidant activity by $K$. africana. Therefore, the analysed plant extracts could be developed into natural antioxidants, which have currently attracted considerable attention.

\subsection{Treatment with Kigelia africana Extracts Did Not Suppress} 15-Lipoxygenase (15-LOX) Enzyme. The plant extracts reconstituted in DMSO were evaluated for their effect on the activity of 15 -LOX, and the results expressed as $\mathrm{IC}_{50}$ values are presented in Table 2. SPK04 and KFM05 did not inhibit 15 -LOX as their IC $_{50}$ values were $>1000 \mu \mathrm{g} / \mathrm{mL}$. KFM02 slightly inhibited $15-\mathrm{LOX}$ although it was still a very poor inhibitor with an $\mathrm{IC}_{50}$ value $>307.12 \pm 4.68 \mu \mathrm{g} / \mathrm{mL}$. Compared to the $\mathrm{IC}_{50}$ of the positive control quercetin $(24.69 \pm 1.43 \mu \mathrm{g} / \mathrm{mL})$, none of the plant extracts inhibited the 15 -LOX enzyme. The isomeric enzyme, 15 -LOX, plays a role 
TABLE 1: Percentage ABTS radical scavenging activity of Kigelia africana extracts.

\begin{tabular}{lcccc}
\hline Concentrations $(\mathrm{mg} / \mathrm{mL})$ & \multicolumn{3}{c}{ ABTS radical scavenging activity $(\mathrm{mean} \% \pm$ SEM $(n=3)$} \\
& SPK04 & KFM02 & KFM05 & Ascorbic acid*** \\
\hline 100.00 & $99.37 \pm 0.56$ & $109.12 \pm 14.32$ & $100.33 \pm 1.11$ & $103.95 \pm 4.09$ \\
50.00 & $99.10 \pm 0.89$ & $85.34 \pm 14.35$ & $99.70 \pm 0.52$ & $104.63 \pm 4.64$ \\
25.00 & $83.7 \pm 21.01$ & $47.48 \pm 18.09$ & $81.52 \pm 16.20$ & $99.52 \pm 0.88$ \\
12.50 & $74.94 \pm 3.68$ & $29.77 \pm 16.76$ & $51.39 \pm 13.55$ & $100.09 \pm 0.22$ \\
6.25 & $45.83 \pm 8.75$ & $27.14 \pm 8.94$ & $31.21 \pm 13.55$ & $95.30 \pm 4.92$ \\
3.13 & $35.82 \pm 0.00$ & $19.75 \pm 6.85$ & $20.35 \pm 2.96$ & $99.73 \pm 0.27$ \\
1.56 & $18.03 \pm 4.25$ & $15.3 \pm 0.88$ & $13.92 \pm 13.30$ & $99.97 \pm 0.12$ \\
\hline
\end{tabular}

${ }^{* * *}$ Positive control.

TABLE 2: Antioxidant, 15-LOX inhibition activity, and cytotoxicity of Kigelia africana extracts.

\begin{tabular}{lccr}
\hline Samples & \multicolumn{2}{c}{$\mathrm{IC}_{50}$ values $(\mu \mathrm{g} / \mathrm{mL})$} & $\begin{array}{c}\mathrm{LC} \mathrm{C}_{50} \text { values }(\mu \mathrm{g} / \mathrm{mL}) \\
\text { Cytotoxicity on Vero cells }\end{array}$ \\
\hline SPK04 & ABTS assay & 15-LOX inhibition & $0.32 \pm 0.11$ \\
KFM02 & 4.28 & $>1000$ & $0.20 \pm 0.01$ \\
KFM05 & 21.29 & $307.12 \pm 4.68$ & $0.26 \pm 0.12$ \\
Ascorbic acid*** & 19.47 & $>1000$ & $\mathrm{ND}$ \\
Quercetin*** & $-0.02 \pm 0.00$ & $24.69 \pm 1.43$ & $\mathrm{ND}$ \\
Doxorubicin*** & $\mathrm{ND}$ & $\mathrm{ND}$ & $0.01 \pm 0.00$ \\
\hline
\end{tabular}

**** Positive control; ND: not detected. Values are expressed as mean \pm SEM.

in many inflammatory disorders and is involved in the synthesis of leukotrienes from arachidonic acids. Biologically active leukotrienes are mediators of many proinflammatory and allergic reactions; therefore, the inhibition of the synthesis of leukotrienes by 15 -LOX is considered as an important therapeutic strategy [36]. Therefore, the extracts were not able to block the formation of leukotrienes via the arachidonic acid pathway by inhibiting lipoxygenase.

3.3. Kigelia africana Extracts Are Not Cytotoxic to Vero Monkey Kidney Cells. Before selection of extracts for further anti-inflammatory analyses, their toxicity on normal mammalian cells has to be established. It is of paramount importance that only nontoxic extracts be subjected to further anti-inflammatory analyses. Our results indicated that all the analysed plant extracts were safe on Vero cells at the highest concentration tested when compared with the positive control (doxorubicin) which had an $\mathrm{LC}_{50}$ of $0.01 \pm 0.00 \mu \mathrm{g} / \mathrm{mL}$ (Table 2). SPK04 was the safest extract, followed by KFM05 and KFM02 with $\mathrm{LC}_{50}$ values of $0.32 \pm 0.11,0.26 \pm 0.12$, and $0.20 \pm 0.01 \mu \mathrm{g} / \mathrm{mL}$, respectively. Doxorubicin is a standard drug commonly used to treat leukaemia and Hodgkin's lymphoma, as well as cancers of the bladder, breast, stomach, lung, and ovaries, among others [37].

3.4. Treatment of LPS-Stimulated RAW 264.7 Cells with Kigelia africana Extracts Inhibits Nitric Oxide (NO) Production. The suppression effect of the extracts on NO production is presented in Table 3. Nitric oxide is a toxic free radical produced by macrophages in response to LPS via oxidation of the terminal guanidine nitrogen atom from
TABle 3: Inhibition of nitric oxide (NO) production by Kigelia africana extracts.

\begin{tabular}{lccc}
\hline Samples & $\begin{array}{c}\text { Concentration } \\
(\mu \mathrm{g} / \mathrm{mL})\end{array}$ & $\begin{array}{c}\text { \% NO } \\
\text { inhibition }\end{array}$ & \% cell viability \\
\hline \multirow{3}{*}{ KFM02 } & 1.60 & $35.35 \pm 14.86$ & $113.21 \pm 16.26$ \\
& 12.50 & $46.55 \pm 14.71$ & $96.99 \pm 6.16$ \\
& 50.00 & $55.82 \pm 12.00$ & $94.95 \pm 2.86$ \\
SPK04 & 100.00 & $54.83 \pm 8.18$ & $99.88 \pm 3.57$ \\
& 1.60 & $42.23 \pm 16.07$ & $112.79 \pm 15.01$ \\
& 12.50 & $44.87 \pm 15.74$ & $101.72 \pm 10.90$ \\
KFM05 & 50.00 & $50.40 \pm 10.48$ & $97.65 \pm 9.97$ \\
& 100.00 & $59.65 \pm 4.05$ & $97.75 \pm 10.96$ \\
& 1.60 & $37.16 \pm 18.86$ & $104.95 \pm 12.93$ \\
& 12.50 & $54.65 \pm 9.83$ & $100.39 \pm 5.87$ \\
Quercetin & 50.00 & $59.67 \pm 3.50$ & $99.41 \pm 0.73$ \\
& 100.00 & $63.43 \pm 6.08$ & $95.34 \pm 4.14$ \\
& 1.60 & $64.17 \pm 7.01$ & $97.53 \pm 5.03$ \\
& 12.50 & $90.57 \pm 3.94$ & $83.52 \pm 3.87$ \\
Doxorubicin & 50.00 & $91.05 \pm 5.99$ & $61.31 \pm 2.19$ \\
& 100.00 & $94.37 \pm 3.31$ & $57.05 \pm 7.66$ \\
& 2.00 & & $89.17 \pm 5.65$ \\
& 4.00 & & $60.22 \pm 5.19$ \\
& 10.00 & & $15.55 \pm 6.72$ \\
& 20.00 & & $4.23 \pm 4.06$ \\
\hline
\end{tabular}

Values are expressed as mean \pm SEM.

L-arginine by nitric oxide synthase (NOS) [38]. Inducible NOS is involved in overproduction of NO in response to proinflammatory mediators such as IL-1F3, TNF- $\alpha$, and bacterial LPS [39]. While a small amount of NO synthesized by endothelial NOS (eNOS) and neuronal NOS (nNOS) is essential for maintaining homeostasis, a significantly 
increased amount of NO synthesized by iNOS participates in provoking inflammatory process and acts synergistically with other inflammatory mediators. Hence, to control its production is a principal focus in an anti-inflammatory investigation. In this study, the extracts had a concentrationdependent inhibition of $\mathrm{NO}$ production. At the lowest concentration $(1.6 \mu \mathrm{g} / \mathrm{mL})$, KFM02 released the lowest amount of NO $(35.35 \pm 14.86 \%)$, therefore having the best NO inhibition capacity and highest cell viability $(113.21 \pm 16.26 \%)$. Likewise, at the highest concentration $(100 \mu \mathrm{g} / \mathrm{mL})$, KFM02 released the lowest amount of NO $(54.83 \pm 8.18 \%)$, having the best NO inhibition capacity and highest cell viability $(99.88 \pm 3.57 \%)$. All the extracts compared well with the standard (quercetin) at both low $(64.17 \pm 7.01 \%$ inhibition/97.53 $\pm 5.03 \%$ cell viability) and high concentrations $(94.37 \pm 3.31 \%$ inhibition $/ 57.05 \pm 7.66 \%$ cell viability). A slight reduction in cell viability was noticeable as the concentration increased, yet it was clear that even at the highest concentration $(100 \mu \mathrm{g} / \mathrm{mL})$, the percentage of cell viability for all the tested extracts remained above $90 \%$, inferring a noncytotoxic concentration. Therefore, among the extracts, KFM02 was the best NO inhibitor with high cell viability. Nonetheless, all the extracts had a strong ability to inhibit NO production while leaving normal mammalian cells unaffected. The inhibition of NO production by plant extracts may be due to the inhibition of iNOS expression [40]. The extracts in our study had good inhibitory activity on NO production and a low cytotoxicity; therefore, they could be used to mitigate the propagation of inflammation by NO. The reduction of NO is also associated with the reduction of oxidative stress [41].

3.5. Kigelia africana Extracts Strongly Suppress Cyclooxygenase-2 (COX-2) Enzyme. COX-2 is an inducible enzyme which causes the production of PGs and is closely associated with acute and chronic inflammatory disorders [42]. Prostaglandins produced by COX-2 play an important role in the physiological functions of some tissues [43]. Despite some positive features, expression of COX-2 is high in LPS-stimulated inflammation-related cell types (macrophages and mast cells) [44]. The results of the COX-2 study are presented in Figure 1. At the highest concentration $(200 \mu \mathrm{g} / \mathrm{mL})$, SPK04 was the best COX-2 inhibitor, followed by KFM02 and KFM05. At $200 \mu \mathrm{g} / \mathrm{mL}$, SPK04 and KFM02 were better COX-2 inhibitors than quercetin, the untreated control. At $100 \mu \mathrm{g} / \mathrm{mL}$, SPK04 was the best COX-2 inhibitor, followed by KFM02 and KFM05. At the same concentration, SPK04 and KFM02 were also better COX-2 inhibitors than quercetin and compared well with the untreated control. At the lowest concentration of $50 \mu \mathrm{g} / \mathrm{mL}$, KFM05 was the best COX-2 inhibitor, followed by SPK04 and KFM02. At this concentration, KFM05 and SPK04 were better inhibitors than quercetin. At $50 \mu \mathrm{g} / \mathrm{mL}$, KFM02 had the same COX-2 inhibition capacity as L-NAME, which is an inhibitor of NO synthesis. Overall, SPK04 was the best COX-2 inhibitor, followed by KFM05 and KFM02. Our study results showed that the tested plant extracts had higher COX-2 inhibitory effect at the same concentration as quercetin. The COX-2

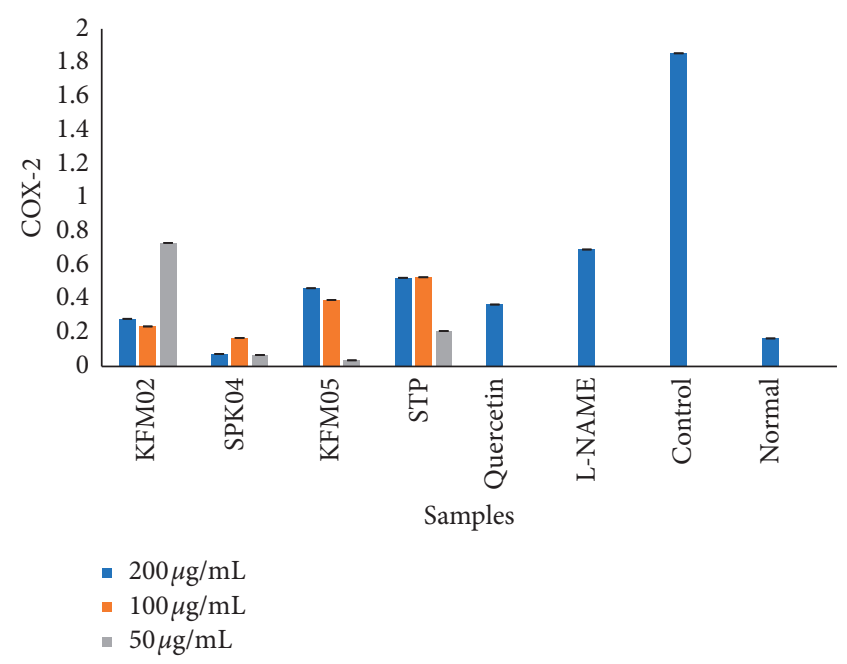

FIgURE 1: Inhibition of cyclooxygenase-2 enzyme activity by $K$. africana aqueous, methanol, and acetone extracts.

inhibitory capacity of the plant extracts being better than that of the standard is evidence of the potency of these extracts in inhibiting COX-2 enzyme activity. The COX-2 inhibitory capacity of these extracts may be explained by the presence of tannins [45]. Tannins affect highly purified enzyme-based targets due to their ability to bind strongly with proteins and this may lead to the inhibition of PG synthesis through blocking the COX enzymes. For antiinflammatory herbal extracts or herbal-derived compounds, inhibition of COX-2 has commonly been found to be their molecular target [44].

Eldeen and Van Staden [46] reported the COX-1 and COX-2 inhibitory effect of $K$ africana leaf ethanol and bark dichloromethane extracts. Whereas not much has been reported on the COX-2 inhibitory effect of K. africana, other studies have reported the inhibitory effect of COX by medicinal plants. Seven lignans and one dihydrochalcone isolated from the leaves of Pleurothyrium cinereum and Ocotea macrophylla were found to be potent inhibitors of COX-2 [47]. Ethyl acetate-soluble extract of the stems of Macrococculus pomiferus was found to inhibit COX-2 [48]. (S)-Coriolic acid and ( \pm )-glycerol 1-monolinolate isolated from ethyl acetate-soluble extract of the seeds of Hernandia ovigera showed selective inhibitory activity with cyclooxygenase-2 [49]. The compound 2,4,5-trimethoxybenzaldehyde isolated from Daucus carota seed extracts inhibited COX-2 enzyme very significantly at a concentration of $100 \mu \mathrm{g} / \mathrm{mL}$ [50]. These studies are evidence of the anti-inflammatory activity of plant extracts through COX inhibition although more research needs to be conducted regarding the COX-2 inhibitory effect of all $K$. africana plant extracts including their mechanisms of action.

3.6. Kigelia africana Extracts Suppress Expression of Proinflammatory Cytokines and Have No Effect on Anti-Inflammatory Cytokine Expression. Cytokines are extremely important for the maintenance of optimum inner environment of our system and for protection from injurious 
agents. However, they should be regulated and kept at favourable levels. Accumulation of a high level of proinflammatory cytokines amplifies inflammation due to the interdependency of one on the other as the production of proinflammatory cytokines works in a cascade mechanism by downstream effects of earlier released cytokines [51]. For example, IL-1 stimulates TNF- $\alpha$ and IL-6 [52]; meanwhile, the prostaglandin-E2 (PGE2) promotes the release of IL-6. Therefore, suppressing the production of a cytokine may influence the reduction of another dependent cytokine. The major proinflammatory cytokines that are responsible for early responses, namely, IL- $1 \alpha$, IL- $1 \beta$, IL- 6 , and TNF- $\alpha$, are elevated in LPS-induced macrophages. Interleukin-6 (IL-6), interleukin- $1 \beta$ (IL- $1 \beta$ ), and TNF- $\alpha$ participate in the prolonging of chronic inflammation. Therefore, these cellular messengers should be mitigated as a measure to avoid further inflammatory process. Interleukin-10 is an anti-inflammatory cytokine which plays a central role in limiting host immune response to pathogens, thereby preventing damage to the host and maintaining normal tissue homeostasis. Unlike proinflammatory cytokines, IL-10 cellular messengers should be promoted to avoid further inflammatory process.

In this study, exposure of the cells with LPS significantly increased the production of IL-6, IL- $1 \beta$, and TNF- $\alpha$. However, treatment with Kigelia extracts suppressed the production of the cytokines in some cases, and in others, there was no suppression (Figure 2). At the highest concentration $(200 \mu \mathrm{g} / \mathrm{mL})$, KFM05 expressed a strong inhibitory effect on IL1- $\beta$ which was similar to that of the standard (quercetin). This was followed by SPK04, and KFM02 had the least inhibitory effect although it was higher than that of the untreated control and not significantly different from L-NAME inhibition capacity. At the lowest concentration $(50 \mu \mathrm{g} / \mathrm{mL})$, KFM05 still had the best IL- $1 \beta$ inhibitory effect although it was much lower than the standard but not significantly different from SPK04. At this concentration, KFM02 had no inhibitory effect since it was not significantly different from the control where the cells were stimulated but not treated. Therefore, at all concentrations $(200,100$, and $50 \mu \mathrm{g} / \mathrm{mL}$ ), KFM05 was the best IL- $1 \beta$ inhibitor, followed by SPK04 and KFM02. At 200 and $100 \mu \mathrm{g} / \mathrm{mL}$, the inhibitory effect of KFM05 was not significantly different from the standard, making it an excellent IL1- $\beta$ inhibitor.

KFM05 had the highest IL-6 inhibition capacity at $200 \mu \mathrm{g} / \mathrm{mL}$ followed by SPK04 while KFM02 had the least inhibitory effect which was not significantly different from the untreated control. Implying that KFM02 did not inhibit cytokine IL- 6 at $200 \mu \mathrm{g} / \mathrm{mL}$. At $100 \mu \mathrm{g} / \mathrm{mL}$, KFM05 was the best IL- 6 inhibitor followed by SPK04 and very little inhibitory effect was observed for KFM02. At the lowest concentration $(50 \mu \mathrm{g} / \mathrm{mL})$, KFM05 had the highest IL-6 inhibitory effect. Extracts SPK04 and KFM02 had fairly good inhibition effect and there was no significant difference in IL-6 inhibitory effect by these two extracts at $50 \mu \mathrm{g} / \mathrm{mL}$. KFM05 was the best IL-6 inhibitor at all concentrations, followed by SPK04, and KFM02 had the least inhibition. At 100 and $50 \mu \mathrm{g} / \mathrm{mL}$, KFM02 had the same IL-6 inhibition capacity. There was no significant difference between
L-NAME inhibitory effect and the untreated control. This implies that L-NAME had barely any inhibitory effect on IL6. The results are presented in Figure 2.

KFM05 had the highest TNF- $\alpha$ inhibition effect at $200 \mu \mathrm{g} / \mathrm{mL}$ (Figure 2). At the same concentration, the inhibitory effect of SPK04 and KFM02 was not significantly different. At $100 \mu \mathrm{g} / \mathrm{mL}$, KFM02 had the highest TNF- $\alpha$ inhibitory effect followed by SPK04 and KFM05. The inhibitory effects of KFM05 at 200 and $100 \mu \mathrm{g} / \mathrm{mL}$ were not significantly different to those of SPK04. At the lowest concentration $(50 \mu \mathrm{g} / \mathrm{mL})$, SPK04 had the highest TNF- $\alpha$ inhibition effect followed by KFM02, and KFM05 had the least inhibition effect. Generally, at $100 \mu \mathrm{g} / \mathrm{mL}$, all the three extracts had the highest inhibition capacity for TNF- $\alpha$. Furthermore, at all concentrations, the three plant extracts had a higher inhibitory effect for TNF- $\alpha$ than the standard (quercetin) and the untreated control. L-NAME had an inhibitory effect on TNF- $\alpha$. Therefore, the extracts investigated could inhibit the expression of IL- 6 , IL- $1 \beta$, and TNF- $\alpha$ molecules which have been demonstrated as the target for many anti-inflammatory medicinal plants and their compounds [7].

Interleukin-10 is an anti-inflammatory cytokine structurally related to interferons [53] that plays a central role in limiting the immune response to pathogens, preventing damage to the host, and maintaining normal tissue homeostasis. All the tested extracts had no effect on the antiinflammatory cytokine IL-10 (Figure 2). L-NAME had no inhibitory effect on IL-10 while the standard greatly inhibited IL-10.

The good antioxidant and anti-inflammatory activity of K. africana fruit extracts may be explained by the presence of verminoside [54], an iridoid glycoside. In vitro assays have confirmed that verminoside has significant anti-inflammatory effects, inhibiting both iNOS expression and NO release in the LPS-induced J774.A1 macrophage cell line [55]. Using the carrageenan-induced paw edema model in rats, as well as the acetic acid-induced writhing, hot plate, and formalininduced paw licking models in mice, Carey et al. [56] reported that the flower extract of $K$. africana exhibited significant anti-inflammatory and analgesic activities at doses of 100,200 , and $400 \mathrm{mg} / \mathrm{kg}$ body weight in rats and mice. Furthermore, the methanolic extract of $K$. africana fruit using various in vivo models of inflammation in mice and rats significantly attenuated the inflammation in formaldehyde-induced paw edema, acetic acid-induced vascular permeability, cotton pellet-induced granuloma, estimation of plasma MDA levels, and carrageenan-induced peritonitis models [57]. Verminoside also exhibits cytotoxic activity in the concentration range of 70-355 $\mu \mathrm{M}$ [54]. Hassan et al. [58] reported that $K$. africana extracts have significant wound-healing properties observing a rapid reduction in exudation and scab formation, classical signs of inflammation. The same study also reported that the lethal dose of the leaf extract is greater than $3 \mathrm{~g} / \mathrm{kg}$; this suggests that $K$. africana is safe to be consumed for the treatment of various ailments. It is proposed that the mechanism of action of $K$. africana leaf extracts may be due to its angiogenic and mitogenic potential leading to increased cellular 

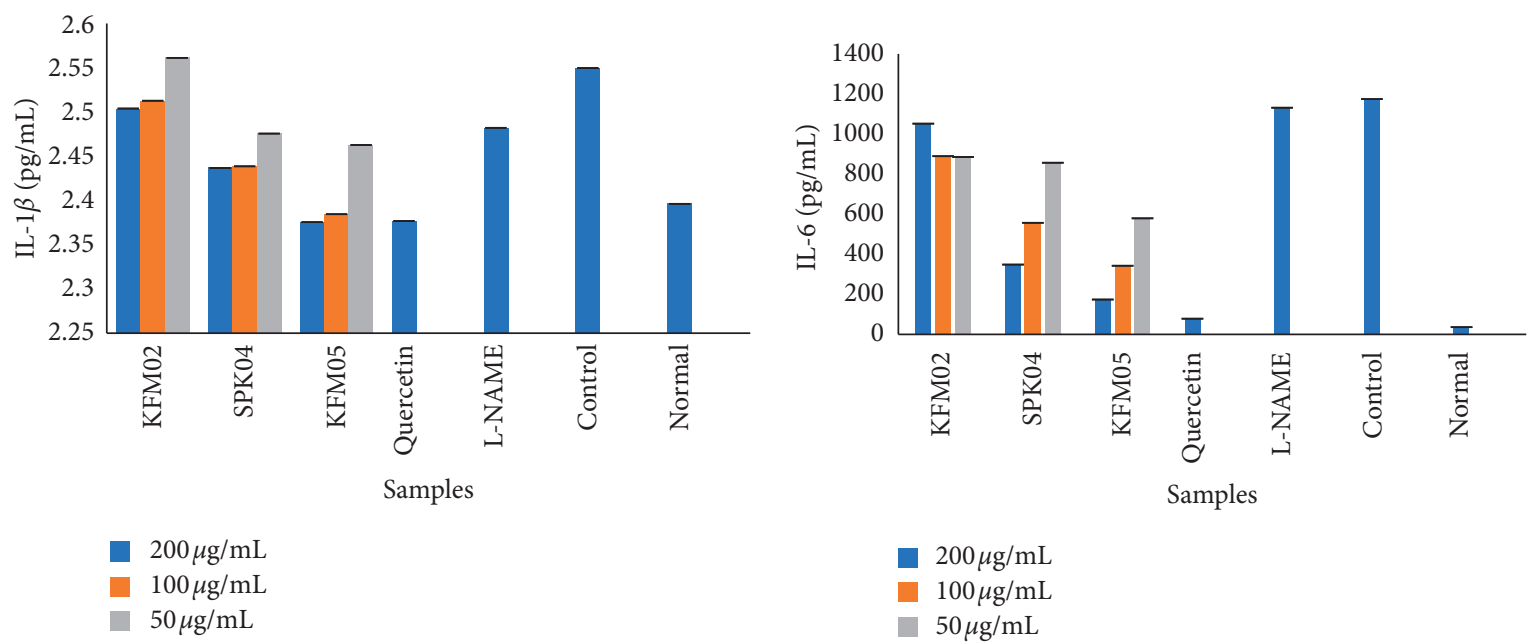

(a)

(b)
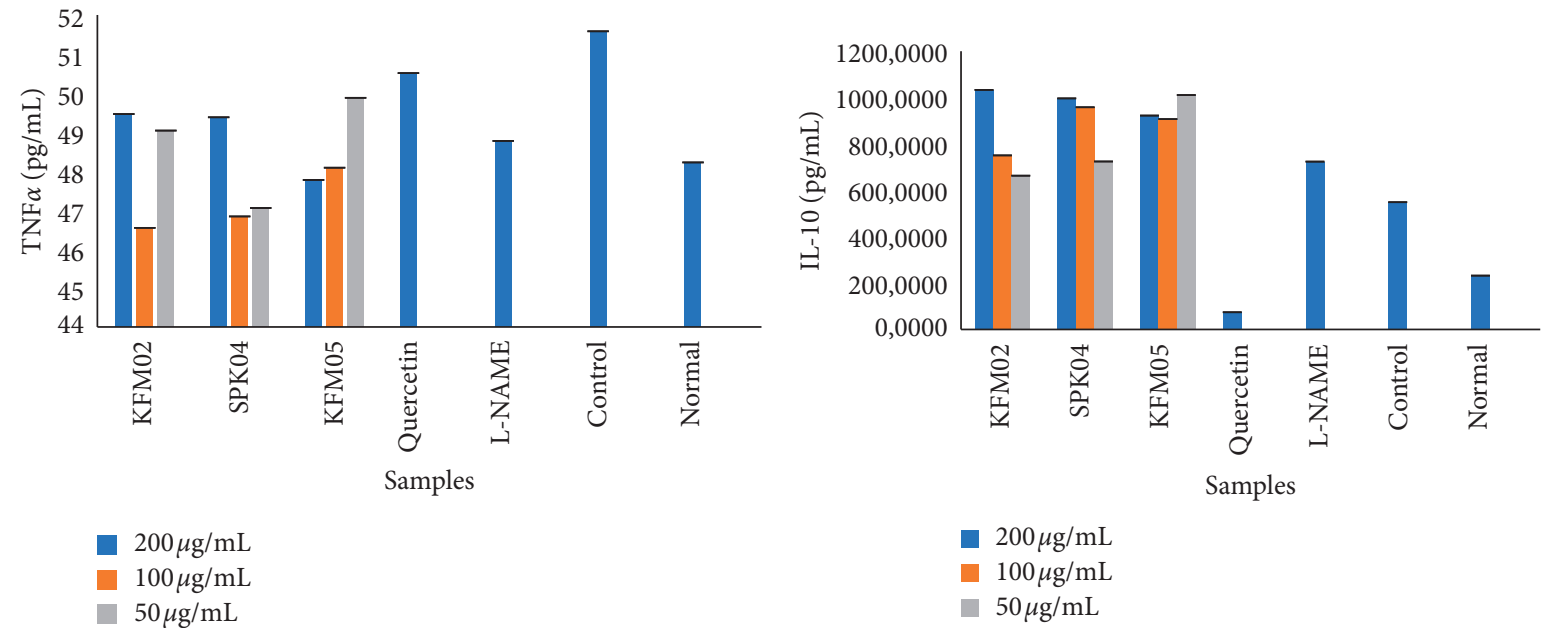

(c)

(d)

FIGURE 2: The effect of K. africana aqueous (KFM02), methanol (SPK04), and acetone (KFM05) extracts on interleukin-6 (IL-6), IL-1 $\beta$, tumor necrosis factor- $\alpha$ (TNF- $\alpha$ ), and IL-10 in LPS-stimulated RAW 264.7 macrophage cells. The values of cytokine production were expressed in $\mathrm{pg} / \mathrm{mL}$, and the data presented were the mean values of three experiments \pm SEM. $p<0.05$, the LPS-treated group versus the control group. Quercetin was used as the standard; the control was made of untreated LPS-stimulated RAW 264.7 macrophage cells, and LNAME (N omega-Nitro-L-arginine methyl ester hydrochloride) is a nitric oxide synthase inhibitor treated with the extracts. (a) Interleukin$1 \beta$ (IL-1 $\beta$ ). (b) Interleukin-6 (IL-6). (c) Tumor necrosis factor- $\alpha$ (TNF- $\alpha$ ). (d) Interleukin-10 (IL-10).

proliferation and collagen synthesis [58], thereby assisting in scar tissue formation and reperfusion of the injured site, thus resolving the sequela of inflammation.

Among the three tested plant extracts, the polymethanolic extract (SPK04) showed more potency in all experiments as compared to the mono extracts KFM05 and KFM02. SPK04 is a combination of K. africana leaves and $S$. campanulata leaves in equal amounts. This extract was made to mimic the traditional preparation of these plants before their usage in wound healing and skin infections [17]. Herbal medicine preparations are made of either a single plant or a combination of more than one plant. When two or more plants are used to make a herbal preparation, the resultant is a polyherbal formulation (PHF). Polyherbalism is more common than single herbal preparations and this also dates to ancient times [59]. The therapeutic effect of a polyherbal is based on the pharmacokinetic and pharmacodynamic synergism of the different herbs in the preparation [60]. Therefore, since in polyherbals a combination of phytochemicals acts on multiple targets at the same time, therapeutic activity is more significant than that of a single herb preparation [61] which may explain the potency of SPK04. The extracting solvents used in this study were water, acetone, and methanol. The methanolic extract (SPK04) showed more potency than the hot water (KFM02) and acetone (KFM05) extracts. The potency of the methanolic extract may be explained by the ability of methanol to extract lower molecular weight polyphenols, whereas water and acetone are good for the extraction of higher molecular weight flavanols [62]. Furthermore, it has been reported that the free radical scavenging activity of $K$. africana may be due to the presence of phenols that can donate the hydrogen atoms 
in their hydroxyl groups [27]. Thus, the potency of SPK04 may be explained by its polyherbal nature and the nature of the extraction solvent used.

\section{Conclusion}

The in vitro antioxidant assays indicate that the tested plant extracts are significant sources of natural antioxidants, which might be helpful in preventing oxidative stress. Additionally, there is a potential that these extracts could be used as additives in the food industry for purposes of providing good protection against oxidative damage. Our study results also indicated that the extracts exhibited antiinflammatory properties by suppressing the expression of proinflammatory cytokines (IL- $1 \beta$, IL-6, and TNF- $\alpha$ ) in LPS-stimulated macrophages and COX-2 enzyme; thus, the hypothesis of the study was accepted. Fortunately, our extracts did not suppress the anti-inflammatory cytokine (IL10) which further justifies their selective inhibitory activity on important cytokines. Lastly, results of this study suggest that the bioactive constituents of $K$. africana extracts and $S$. campanulata in SPK04 had both antioxidant and anti-inflammatory activities. Antioxidants act by scavenging free radicals such as reactive oxygen species, hydroxyl radicals, and nitric oxide while anti-inflammatory mediators act by modulating the activities of proinflammatory enzymes and cytokines. The study also gives insights on $K$. africana's safety to normal mammalian cells. Thus, we recommend further research be conducted to isolate, identify, and characterize the bioactive compounds that are responsible for the activities. Once the active compounds have been isolated, the mechanism of activity can be examined. Prior to clinical use, the in vivo antioxidant and anti-inflammatory activity of these extracts need to be assessed.

$\begin{array}{ll}\text { Abbreviations } \\ \text { DPPH: } & \begin{array}{l}\text { 2,2-Diphenyl-1-picrylhydrazyl } \\ \text { ABTS: }\end{array} \\ & \begin{array}{l}\text { 2,2'-Azino-bis (3-ethylbenzthiazoline-6-sulfonic } \\ \text { acid }\end{array} \\ \text { MTT: } & 3-(4,5-D i m e t h y l t h i a z o l-2-y l)-2,5-d i p h e n y l \\ & \text { tetrazolium bromide } \\ \text { LPS: } & \text { Lipopolysaccharides } \\ \text { ROS: } & \text { Reactive oxygen species } \\ \text { OS: } & \text { Oxidative stress } \\ \text { NO: } & \text { Nitric oxide } \\ \text { PGs: } & \text { Prostaglandins } \\ \text { IL: } & \text { Interleukin } \\ \text { TNF- } \alpha: & \text { Tumor necrosis factor-alpha } \\ \text { ANOVA: } & \text { Analysis of variance } \\ \text { COX-2: } & \text { Cyclooxygenase-2 } \\ \text { 15-LOX: } & \text { 15-Lipoxygenase } \\ \text { PUFAs: } & \text { Polyunsaturated fatty acids } \\ \text { DMSO: } & \text { Dimethylsulphoxide } \\ \text { NSAIDs: } & \text { Nonsteroidal anti-inflammatory drugs } \\ \text { SOD: } & \text { Superoxide dismutase } \\ \text { PBS: } & \text { Phosphate-buffered saline } \\ \text { DMEM: } & \text { Dulbecco's modified Eagle's medium }\end{array}$

L- N-Omega-nitro-L-arginine methyl ester

NAME: hydrochloride.

\section{Data Availability}

All data supporting our findings are adequately included within the article.

\section{Conflicts of Interest}

The authors report no conflicts of interest in this work.

\section{Authors' Contributions}

Alice Nabatanzi and Sanah Nkadimeng performed experiments and data analysis. Alice Nabatanzi wrote the first draft of the manuscript. Lyndy McGaw, Namrita Lall, and John David Kabasa provided facilities, supervised the research, and revised the final manuscript. All authors read and approved the final manuscript.

\section{Acknowledgments}

The authors are thankful to Carnegie Cooperation of New York through Future Africa, University of Pretoria, South Africa, for funding this work. They also express their heartfelt gratitude to all the persons who made this work a success: (i) Professor David Bager (Department of Plant and Soil Sciences, University of Pretoria, South Africa) identified plant collection sites in Lynnwood, Pretoria East, South Africa; (ii) Mr. Gertkltze permitted us to collect Kigelia africana samples from his compound in Lynnwood, Pretoria East, South Africa; (iii) Mr. Roelf Coertze (Farm Manager, University of Pretoria Experimental Farm) permitted us to collect plant samples from the farm; (iii) Mr. Emmanuel (Assistant Farm Manager, University of Pretoria Experimental Farm, South Africa) helped in climbing trees to collect leaves and fruit samples; (iv) Mr. Joseph Lethabo and Mr. Abraham (Drivers, High Performance Centre, Hillcrest Campus, University of Pretoria, South Africa) helped in driving us to and fro plant collection sites; (v) Dr. Kenneth Oberlander (HGWJ Schweickerdt Herbarium, University of Pretoria, South Africa) scientifically identified the plant voucher specimen; and (vi) Mr. William (Phytomedicine Programme, University of Pretoria) helped in grinding all plant samples for laboratory analyses.

\section{References}

[1] N. A. Punchard, C. J. Whelan, and I. Adcock, Journal of Inflammation, vol. 1, no. 1, p. 1, 2004.

[2] F. Conforti, S. Sosa, M. Marrelli et al., "In vivo anti-inflammatory and in vitro antioxidant activities of Mediterranean dietary plants," Journal of Ethnopharmacology, vol. 116, no. 1, pp. 144-151, 2008.

[3] W. Brand-Williams, M. E. Cuvelier, and C. Berset, "Use of a free radical method to evaluate antioxidant activity," $L W T$ Food Science and Technology, vol. 28, no. 1, pp. 25-30, 1995. 
[4] O. Radmark and B. Samuelsson, "5-Lipoxygenase: mechanism of regulation," The Journal of Lipid Research, vol. 50, pp. 40-45, 2009.

[5] C. S. Nworu and P. A. Akah, "Anti-inflammatory medicinal plants and the molecular mechanisms underlying their activities," African Journal of Traditional, Complementary and Alternative Medicines, vol. 12, no. 6, pp. 52-61, 2015.

[6] S. Cuzzocrea, D. P. Riley, A. P. Caputi, and D. Salvemini, "Antioxidant therapy: a new pharmacological approach in shock, inflammation, and ischemia/reperfusion injury," Pharmacological Reviews, vol. 53, no. 1, pp. 135-159, 2001.

[7] R. Newton, "Molecular mechanisms of glucocorticoid action: what is important?" Thorax, vol. 55, no. 7, pp. 603-613, 2000.

[8] K. A. O'Leary, S. de Pascual-Tereasade, P. W. Needs, Y. P. Bao, N. M. O'Brien, and G. Williamson, "Effect of flavonoids and Vitamin E on cyclooxygenase-2 (COX-II) transcription," Mutation Research, vol. 551, no. 1-2, pp. 245-254, 2004.

[9] I. Y. Adam and I. A. Alhameed, "Kigelia africana fruits extracts anti hepato-toxic effects on male wistar rats liver destruction induced by $\mathrm{CCL}_{4}$," Asian Journal of Medical Sciences, vol. 5, no. 1, pp. 26-32, 2013.

[10] L. Chih-Cheng, C. Lu-Te, W. Yuan-Chen et al., "Polyphenol and antioxidant content of Kigelia africana leaves from Ghana," Food, vol. 6, no. 1, pp. 1-5, 2012.

[11] M. Lamorde, J. R. S. Tabuti, C. Obua et al., "Medicinal plants used by traditional medicine practitioners for the treatment of HIV/AIDS and related conditions in Uganda," Journal of Ethnopharmacology, vol. 130, no. 1, pp. 43-53, 2010.

[12] T. Hussain, K. F. Fatima, M. Rafay, S. Shabir, M. Akram, and S. Bano, "Evaluation of antibacterial and antioxidant activity of leaves, fruit and bark of Kigelia africana," Pakistan Journal of Botany, vol. 48, no. 1, pp. 277-283, 2016.

[13] F. Ursini, M. Maiorino, P. Morazzoni, A. Roveri, and G. Pifferi, "A novel antioxidant flavonoid (IdB 1031) affecting molecular mechanisms of cellular activation," Free Radical Biology and Medicine, vol. 16, no. 5, pp. 547-553, 1994.

[14] J. Akintunde, D. Akintunde, E. Irondi, K. Babaita, R. Labaika, and O. Sunday, "Antioxidants from stem bark of Kigelia africana inhibits free radicals and membrane lipid damage in rat testes in vitro," Oxidants and Antioxidants in Medical Science, vol. 5, no. 2, p. 63, 2016.

[15] P. Namita, R. Mukesh, and K. Tirath, "Evaluation of antiinflammatory potential of Kigelia pinnata leaf extract in wistar rats," Asian Journal of Pharmaceutical and Clinical Research, vol. 5, no. 1, pp. 95-97, 2012.

[16] A. Arkhipov, J. Shalom, B. Matthews, and I. E. Ian Edwin Cock, "Metabolomic profiling of Kigelia africana extracts with anti-cancer activity by high resolution tandem mass spectroscopy," Pharmacognosy Communications, vol. 4, no. 4, pp. 10-32, 2014.

[17] WCSP (World Checklist of Selected Plant Families), World Checklist of Selected Plant Families, Facilitated by the Royal Botanic Gardens, 2020.

[18] M. Vijayasanthi, A. Doss, and K. V. Kannan, "Anti-inflammatory activity of Spathodea campanulata P. Beauv. leaves against carrageenan induced paw edema," Bio TechnologyElixir International Journal, vol. 78, pp. 29450-29452, 2015.

[19] B.-E. Van Wyk, H. de Wet, and F. R. Van Heerden, "An ethnobotanical survey of medicinal plants in the Southeastern Karoo, South Africa," South African Journal of Botany, vol. 74, no. 4, pp. 696-704, 2008.

[20] O. J. Owolabi and K. I. E. Omogbai, “Analgesic and Antiinflammatory activities of the ethanolic stem bark extract of
Kigelia africana (Bignoniaceae)," African Journal of Biotechnology, vol. 6, no. 5, p. 582585, 2007.

[21] R. Re, N. Pellegrini, A. Proteggente, A. Pannala, M. Yang, and C. Rice-Evans, "Antioxidant activity applying an improved ABTS radical cation de-colourization assay," Free Radical Biological Medicine, vol. 26, no. 9-10, pp. 1231-1237, 1999.

[22] B. J. Gaffney, "Lipoxygenases: structural principles and spectroscopy," Annual Review of Biophysics and Biomolecular Structure, vol. 25, no. 1, pp. 431-459, 1996.

[23] T. Mosmann, "Rapid colorimetric assay for cellular growth and survival: application to proliferation and cytotoxicity assays," Journal of Immunological Methods, vol. 65, no. 1-2, pp. 55-63, 1983.

[24] Z. Hodzic, H. Pasalic, A. Memisevic, M. Srabovic, M. Saletovic, and M. Poljakovic, "The influence of total phenols content on antioxidant capacity in the whole grain extracts," European Journal of Scientific Research, vol. 28, pp. 471-477, 2009.

[25] J. O. Olugbami, M. A. Gbadegesin, and O. A. Odunola, "In vitro evaluation of the antioxidant potential, phenolic and flavonoid contents of the stem bark ethanol extract of Anogeissus leiocarpus," African Journal of Medicine and Medical Sciences, vol. 43, no. Suppl 1, pp. 1-109, 2014.

[26] V. Dhriti, P. V. Chowdary, J. Rahul, G. Vishank, and B. B. Shivaji, "Free radical scavenging and anti-diabetic activity of Kigelia pinnata," World Journal of Pharmacy and Pharmaceutical Sciences, vol. 3, pp. 1249-1262, 2014.

[27] A. Lugas, J. Hovari, K. V. Sagi, and L. Bíro, "The role of antioxidant phytonutrients in the prevention of diseases," Acta Biologica Szegediensis, vol. 47, no. 1-4, pp. 119-125, 2003.

[28] I. M. Ahmad, M. Y. Abdalla, N. H. Mustafa, E. Y. Qnais, and F. A. Abdulla, "Datura aqueous leaf extract enhances cytotoxicity via metabolic oxidative stress on different human cancer cells," Jordan Journal of Biological Sciences, vol. 2, no. 9, p. 1, 2009.

[29] E. Bizimenyera, The potential role of antibacterial, antioxidant and antiparasitic activity of Peltophorum africanum Sond (Fabaceae) extracts in the ethnoveterinary medicine, vol. 83, University of Pretoria, Pretoria, South Africa, 2007, Ph.D. thesis.

[30] E. Mongelli, C. Desmarchelier, J. Rodríguez Talou, J. Coussio, and G. Ciccia, "In vitro antioxidant and cytotoxic activity of extracts of Baccharis coridifolia DC," Journal of Ethnopharmacology, vol. 58, no. 3, pp. 157-163, 1997.

[31] A. Ponnan, R. Perumal, T. S. Sathiyavedu, and R. Arabandi, "Antioxidant activity measured in different solvent fractions obtained from Mentha spicata Linn.: an analysis by ABTS decolorization assay," Asia Pacific Journal of Clinical Nutrition, pp. 119-124, 2006.

[32] B. D’Abrosca, M. DellaGreca, A. Fiorentino, P. Monaco, A. Natale, and P. Oriano, "Structural characterization of phytotoxic terpenoids from Cestrum parqui," Phytochemistry, vol. 66, no. 22, pp. 2681-2688, 2005.

[33] B. D’Abrosca, M. DellaGreca, A. Fiorentino, P. Monaco, and A. Zarrelli, "Low molecular weight phenols from the bioactive aqueous fraction of Cestrum parqui," Journal of Agricultural and Food Chemistry, vol. 52, no. 13, pp. 4101-4108, 2004.

[34] M. Della Greca, A. Fiorentino, P. Monaco, L. Previtera, and A. Zarrelli, "Effusides I-V: 9,10-dihydrophenanthrene glucosides from Juncus effusus," Phytochemistry, vol. 40, no. 2, pp. 533-535, 1995.

[35] A. Olubunmi, G. Olatunji, A. Oluyomi, S. Oluremi, S. Fayemi, and S. O. Fayemi, "Antioxidant and antimicrobial activity of 
cuticular wax from Kigelia africana," Fabad Journal of Pharmaceutical Sciences, vol. 34, no. 4, 2009.

[36] I. Schneider and F. Bucar, "Lipoxygenase inhibitors from natural plant sources. Part 1: medicinal plants with inhibitory activity on arachidonate 5-lipoxygenase and 5-lipoxygenase [sol ]cyclooxygenase," Phytotherapy Research, vol. 19, no. 2, pp. 81-102, 2005.

[37] O. Tacar, P. Sriamornsak, and C. R. Dass, "Doxorubicin: an update on anticancer molecular action, toxicity and novel drug delivery systems," Journal of Pharmacy and Pharmacology, vol. 65, no. 2, pp. 157-170, 2013.

[38] V. Mollace, C. Muscoli, E. Masini, S. Cuzzocrea, and D. Salvemini, "Modulation of prostaglandin biosynthesis by nitric oxide and nitric oxide donors," Pharmacological Reviews, vol. 57, no. 2, pp. 217-252, 2005.

[39] R. C. Venema, H. Ju, R. Zou, J. W. Ryan, and V. J. Venema, "Subunit interactions of endothelial nitric-oxide synthase," Journal of Biological Chemistry, vol. 272, no. 2, pp. 1276-1282, 1997.

[40] C.-J. Lee, L.-G. Chen, W.-L. Liang, and C.-C. Wang, “Antiinflammatory effects of Punica granatum Linne in vitro and in vivo," Food Chemistry, vol. 118, no. 2, pp. 315-322, 2010.

[41] P. Arulselvan, M. T. Fard, W. S. Tan et al., "Role of antioxidants and natural products in inflammation," Oxidative Medicine and Cellular Longevity, vol. 2016, Article ID 5276130, 2016.

[42] R. W. McMurray and K. J. Hardy, "COX-2 inhibitors: today and tomorrow," The American Journal of the Medical Sciences, vol. 323, no. 4, pp. 181-189, 2002.

[43] B. N. Cronstein, "Cyclooxygenase-2-selective inhibitors: translating pharmacology into clinical utility," Cleveland Clinic Journal of Medicine, vol. 69, pp. 13-19, 2002.

[44] P. Needleman and P. Isakson, "The discovery and function of COX-2," Journal of Rheumatology, vol. 24, pp. 6-8, 1997.

[45] M. M. Cowan, "Plant products as antimicrobial agents," Clinical Microbiology Reviews, vol. 12, no. 4, pp. 564-582, 1999.

[46] I. M. S. Eldeen and J. Van Staden, "Cyclooxygenase inhibition and antimycobacterial effects of extracts from Sudanese medicinal plants," South African Journal of Botany, vol. 74, no. 2, pp. 225-229, 2008.

[47] E. D. Coy-Barrera and L. E. Cuca-Suarez, "In vitro anti-inflammatory effects of naturally-occurring compounds from two lauraceae plants," Anais da Academia Brasileira de Ciencias, vol. 83, no. 4, pp. 1397-1402, 2011.

[48] B. N. Su, W. P. Jones, M. Cuendet et al., "Constituents of the stems of Macrococculus pomiferus and their inhibitory activities against cyclooxygenases-1 and -2," Phytochemistry, vol. 65, no. 21, pp. 2861-2866, 2004.

[49] O. Choi, W. Y. Kim, J. S. Kang et al., "Two enzymes in one; two yeast peroxiredoxins display oxidative stress-dependent switching from a peroxidase to a molecular chaperone function," Cell, vol. 117, no. 5, pp. 625-635, 2004.

[50] R. A. Momin, D. L. De Witt, and M. G. Nair, "Inhibition of cyclooxygenase (COX) enzymes by compounds from Daucus carota L. seeds," Phototherapeutic Research, vol. 17, no. 8, pp. 976-979, 2003.

[51] W. Schulte, J. Bernhagen, and R. Bucala, "Cytokines in sepsis: potent immunoregulators and potential therapeutic targets-an updated view," Mediators of Inflammation, vol. 2013, Article ID 165974, 16 pages, 2013

[52] K. Tanabe, R. Matsushima-Nishiwaki, S. Yamaguchi, H. Iida, S. Dohi, and O. Kozawa, "Mechanisms of tumor necrosis factor- $\alpha$-induced interleukin-6 synthesis in glioma cells," Journal of Neuroinflammation, vol. 7, no. 1, p. 16, 2010.

[53] A. Zdanov, C. Schalk-Hihi, and A. Wlodawer, "Crystal structure of human interleukin-10 at $1.6 \AA$ resolution and model of a complex with its soluble receptor," Protein Science Journal, vol. 5, no. 10, pp. 1955-1962, 1996.

[54] A. Narasimha, J. Watanabe, J. Linc et al., "A novel antiatherogenic role for COX-2-potential mechanism for the cardiovascular side effects of COX-2 inhibitors," Prostaglandins \& Other Lipid Mediators, vol. 84, no. 1-2, pp. 24-33, 2007.

[55] P. Picerno, G. Autore, S. Marzocco, M. Meloni, R. Sanogo, and R. P. Aquino, "Anti-inflammatory activity of Verminoside from Kigelia africana and evaluation of cuteneous irritation in cell cultures and reconstituted human epidermis," Journal of Natural Products, vol. 68, pp. 1610-1614, 2005.

[56] M. W. Carey, N. V. Rao, B. R. Kumar, and G. K. Mohan, "Anti-inflammatory and analgesic activities of methanolic extract of Kigelia pinnata DC flower," Journal of Ethnopharmacology, vol. 130, pp. 179-182, 2010.

[57] W. M. Carey, D. Jeevan Mani Babu, N. Venkat Rao, and G. Krishna Mohan, "Anti-inflammatory activity of the fruit of Kigelia pinnata DC," Pharmacologyonline, vol. 2, pp. 234-245, 2008.

[58] S. W. Hassan, M. G. M. Abubakar, R. A. Umar, A. S. Yakubu, H. M. Maishanu, and G. Ayeni, "Pharmacological and toxicological properties of leaf extracts of Kigelia africana (Bignoniaceae)," Journal of Pharmacology and Toxicology, vol. 6, pp. 124-132, 2011.

[59] S. Srivastava, V. K. Lal, and K. K. Pant, "Polyherbal formulations based on Indian medicinal plants as antidiabetic phytotherapeutics," Phytopharmacology, vol. 2, pp. 1-15, 2013.

[60] M. Spinella, "The importance of pharmacological synergy in psychoactive herbal medicines," Alternative Medicine Reviews, vol. 7, pp. 130-137, 2002.

[61] M. S. Chorgade, Drug Discovery and Development, Vol. 2, John Wiley and Sons Inc, Drug Development, Hoboken, NJ, USA, 2007.

[62] J. Dai and R. J. Mumper, "Plant phenolics: extraction, analysis and their antioxidant and anticancer properties," Molecules, vol. 15, no. 10, pp. 7313-7352, 2010. 